\title{
Optimizing the productivity of a coral nursery focused on staghorn coral Acropora cervicornis
}

\author{
Kathryn E. Lohr ${ }^{1,5, *}$, Sonia Bejarano ${ }^{1}$, Diego Lirman ${ }^{2}$, Stephanie Schopmeyer ${ }^{2}$, \\ Carrie Manfrino ${ }^{3,4}$
}

${ }^{1}$ Central Caribbean Marine Institute, Little Cayman Research Centre, North Coast Road, Little Cayman, KY3-2501, Cayman Islands

${ }^{2}$ Rosenstiel School of Marine and Atmospheric Science, University of Miami, 4600 Rickenbacker Cswy, Miami, FL 33149, USA

${ }^{3}$ Central Caribbean Marine Institute, PO Box 1461, Princeton, NJ 08540, USA

${ }^{4}$ School of Environmental and Sustainability Sciences, Kean University, 1000 Morris Ave, Union, NJ 07083, USA

${ }^{5}$ Present address: The University of Florida/IFAS, School of Forest Resources and Conservation,

The Florida Aquarium Center for Conservation, 529 Elsberry Rd., Apollo Beach, FL 33572, USA

\begin{abstract}
The rapid decline of the staghorn coral Acropora cervicornis throughout the Caribbean prompted the development of coral gardening as a management strategy to restore wild stocks. Given that coral gardening relies on propagating corals collected from wild donor colonies, it is imperative to optimize growth within a nursery to reduce dependence on wild collections. This study determined the maximum amount of coral that may be clipped from a colony during propagation without causing mortality or decreased growth. We applied 3 experimental treatments to 12 nursery-reared staghorn corals, in which 25,50, or 75\% of the colony's total biomass was removed and fragmented to create additional, smaller fragments. Four additional colonies served as unfragmented controls. Treatment had no effect on colony productivity, defined as the ratio of new tissue growth to initial colony size, over $87 \mathrm{~d}$. Similarly, treatment had no effect on the rate at which colonies developed new branches. Results indicate that $75 \%$ of the biomass of staghorn colonies may be removed without affecting their growth. We anticipate that our observations will have practical applications for maximizing propagation of staghorn coral within nurseries throughout the wider Caribbean while minimizing the impact of this management measure on remnant wild populations.
\end{abstract}

KEY WORDS: Staghorn coral · Restoration · Coral gardening · Coral nursery · Fragmentation • Propagation · Caribbean

\section{INTRODUCTION}

Coral reef ecosystems worldwide have undergone considerable changes resulting from a complex synergy between natural and anthropogenic disturbances (Done 1992, Hughes 1994). Throughout the Caribbean, mortality of reef-building corals followed by the gradual collapse of their skeletal structures has contributed to major ecosystem phase shifts over the last 4 decades (Gardner et al. 2003, Alvarez-Filip et al. 2009). Not only have these shifts been associ-

${ }^{*}$ Corresponding author: kelohr@ufl.edu ated with important losses of biodiversity in benthic communities, but they have also resulted in seemingly locked states of macroalgal dominance (Mumby et al. 2007) and contributed to a region-wide decline in fish fauna (Paddack et al. 2009). Both coral mortality and loss of habitat structure pose serious threats to coastal livelihoods that depend on the goods and services sustained by coral reefs, such as shoreline protection and artisanal fisheries (Bythell \& Sheppard 1993, Rogers \& Beets 2001, Nagelkerken \& Nagelkerken 2004).

() The authors 2015. Open Access under Creative Commons by Attribution Licence. Use, distribution and reproduction are unrestricted. Authors and original publication must be credited. 
The staghorn coral Acropora cervicornis, once a dominant species on a variety of reef habitats throughout the Caribbean (Knowlton et al. 1981, Tunnicliffe 1983, Jackson et al. 2001), suffered widespread mortality following devastating hurricanes between the 1960s and 1980s (Woodley et al. 1981, Aronson \& Precht 2001). In the 1980s, the remaining populations were almost entirely terminated by white band disease (Bythell \& Sheppard 1993, Aronson \& Precht 2001). With the paucity of A. cervicornis and its congener $A$. palmata persisting over the last 4 decades, Caribbean reefs have sustained an important gap in their portfolio of benthic functional groups (Bellwood et al. 2004). Few other Caribbean coral species provide the amount of structural 3dimensionality characteristic of acroporids in shallow high-energy environments (Sheppard et al. 2005, Alvarez-Filip et al. 2009, M. K. Johnson et al. 2011). Therefore, it is unlikely that other reef-building species can substitute their role as barriers against shoreline erosion, and sources of fish and macroinvertebrate refugia. As a means of recognizing the severity of this ecosystem loss, both species were listed as threatened under the US Endangered Species Act (NMFS 2006).

Although patchy and localized recovery of acroporids has been observed recently (Lidz \& Zawada 2013), consistent regional-scale natural recovery of viable populations seems unlikely mainly due to the species' low rates of larval recruitment (Kojis \& Quinn 2001). Coral reef restoration has therefore been adopted as a management strategy with the immediate goal of replacing dead colonies in devastated areas to speed up natural population recovery (Kojis \& Quinn 2001, Epstein et al. 2003). Coral gardening, one of the most common and versatile coral restoration techniques, involves an initial propagation stage in which small portions of wild coral colonies (referred to as donors) are collected and subdivided in smaller fragments. These fragments are then reared on artificial structures within an in situ nursery until they are large enough to be transplanted back to natural reef habitats (Rinkevich 1995, 2000). A. cervicornis is an ideal candidate for nursery rearing because artificial propagation techniques mimic the species' natural asexual fragmentation that is typically induced by storms (Bowden-Kerby 2001). Consequently, nurseries of varying scope and size focused on $A$. cervicornis have been established in a number of locations in the Caribbean (Herlan \& Lirman 2009, M. E. Johnson et al. 2011, Young et al. 2012). In 2012, an A. cervicornis nursery was installed on Little Cayman Island in the Cayman Islands with the goal of analyzing and refining a variety of coral propagation techniques and restoring coral populations on local reefs.

Although relatively cost effective compared to other restoration techniques, rearing corals in nurseries can be costly and labor intensive. Moreover, given the generalized scarceness of wild adult $A$. cervicornis colonies, an imperative objective of nursery initiatives is to maximize nursery productivity whilst collecting the minimum amount of donor tissue (e.g. Herlan \& Lirman 2009). Given the increased popularity of $A$. cervicornis nurseries and the relative ease with which one can be initiated, it is important to investigate the methodological steps that will optimize their performance and yield. A set of best practices for coral gardening with respect to A. cervicornis has been developed, including strategies to minimize impacts on wild donor colonies, improve survivorship of donated branches, and enhance survivorship of transplanted colonies (Lirman et al. 2010, M. E. Johnson et al. 2011). Despite this extensive work, no studies have systematically determined the maximum amount of tissue that can be clipped from a colony during fragmentation without harming it. Investigating this would therefore be a valuable addition to existing nursery guidelines. Such findings have the potential to improve the effectiveness of restoration efforts throughout the Caribbean.

Here we used a small-scale monospecific nursery located on Little Cayman Island as an opportunity to determine what proportion of coral tissue can be clipped off to propagate nursery-reared A. cervicornis without harming donor colonies. We specifically tested whether the percent of the donor colony that is fragmented had an effect on its growth rate in terms of the amount of new growth and the rate of acquisition of new branches. We anticipate that the information presented here will be useful to scientists and conservation practitioners seeking to optimize the artificial propagation of $A$. cervicornis and may ultimately increase outputs of coral restoration efforts.

\section{MATERIALS AND METHODS}

\section{Study area}

This study was conducted in 2013 during the initial propagation stage of the monospecific Acropora cervicornis nursery maintained by the Central Caribbean Marine Institute and the Cayman Islands De- 
partment of Environment on Little Cayman Island in the Cayman Islands. The nursery is located $400 \mathrm{~m}$ off the north coast of the island within the Bloody Bay Marine Park $\left(19.699^{\circ} \mathrm{N}, 80.060^{\circ} \mathrm{W}\right)$ on a wide area of flat carbonate pavement in the shallow portion of the forereef $(\sim 6.5 \mathrm{~m})$. It was first populated in September 2012 with 58 fragments collected from 4 adult colonies located at geographically distinct locations within 2 sites off the southeast coast of the island. For the purpose of this study, the 4 adult colonies were assumed to be dissimilar genotypes. Fragments were suspended in mid-water by attaching them to 3 line nursery structures, consisting of 3-strand polypropylene line ( $10 \mathrm{~m}$ in length) suspended by a polystyrene fishing float, and have since grown steadily without the incidence of coral disease or corallivore predation. The propagation stage of the nursery began in March 2013 when 16 first-generation colonies ranging in size from 31 to $103 \mathrm{~cm}$ (mean $\pm \mathrm{SE}=48.19$ \pm 4.74 ) were selected for further fragmentation.

To determine what level of fragmentation could maximize the productivity of the nursery without affecting growth rate of the donor colony, 3 fragmentation treatments were selected and 4 replicate firstgeneration colonies were assigned to each treatment. Fig. 1 provides a schematic of the experimental design. To account for the potential variability in growth rate among the 4 genotypes, 1 colony of each genotype was assigned to each treatment. First-generation colonies were fragmented such that 25,50, and $75 \%$ of their total size was clipped to generate new (second-generation) fragments. Four first-generation colonies were left intact and served as experimental controls. During this propagation stage, between 1 and 9 second-generation fragments of approximately $5 \mathrm{~cm}$ in length were obtained from each first-generation parent colony depending on the size of the parent colony and the treatment assigned. A total of 48 second-generation fragments were generated.

Control and experimental second-generation fragments were haphazardly distributed on a suspended PVC tree (Nedimyer et al. 2011) within the nursery to avoid spatial clustering of colonies of the same genotype or treatment. For the purpose of this study, we focused on monitoring the growth rate of first-generation fragments by inspecting these initially in March 2013, and 35, 70, and 83 d later. During inspections, each colony's total number of branches equaling at least $1.5 \mathrm{~cm}$ in length was counted, and its total linear extension to the nearest $\mathrm{cm}$ was measured in situ using rulers (e.g. M. E. Johnson et al. 2011).

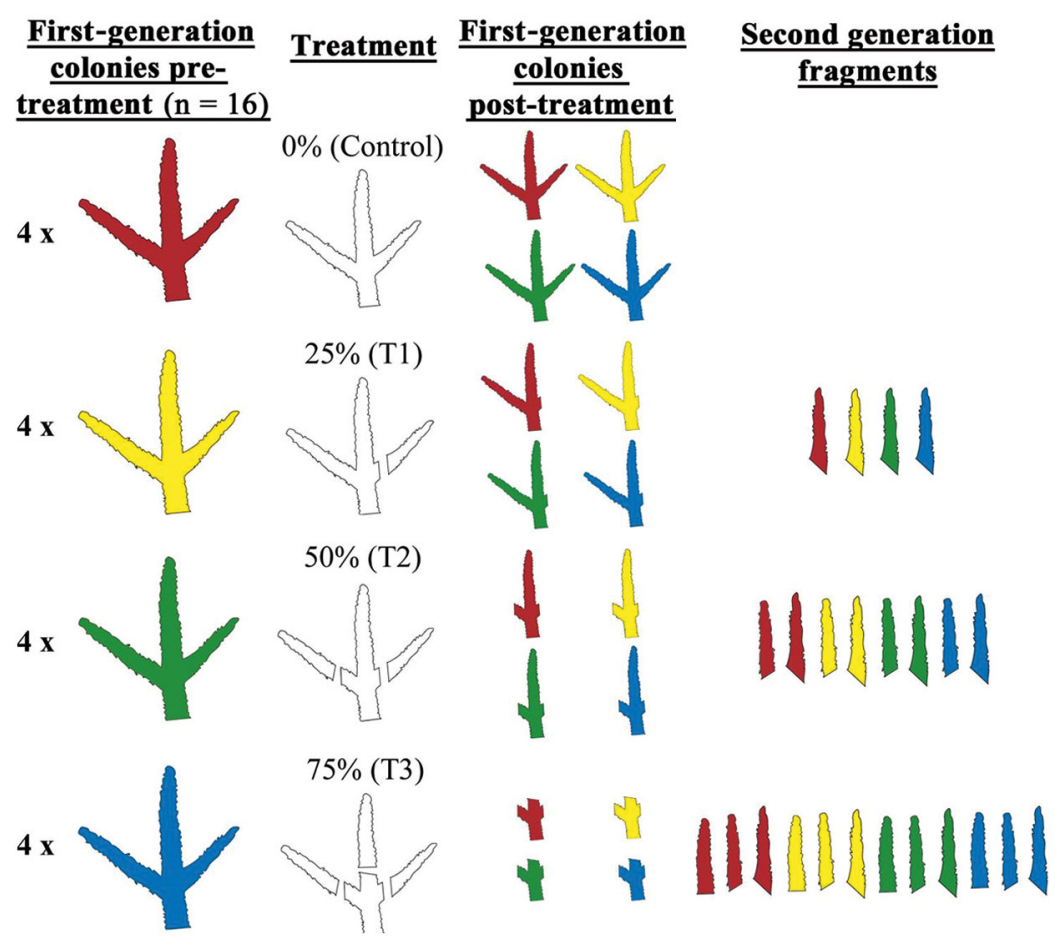

Fig. 1. Experimental design used during this study, illustrating the fragmentation treatments and the level of replication per treatment. Colors represent different genotypes of staghorn coral Acropora cervicornis. Four first-generation colonies from each genotype were fragmented during the experiment

\section{Data analysis}

The normalized increase in size $(p)$ was calculated for each colony using the expression:

$$
p=\frac{x_{f}-x_{i}}{x_{i}}
$$

where $x_{f}$ corresponds to the size of the fragment at a given time point, and $x_{i}$ is the size of the fragment at the beginning of the study.

To identify the fragmentation treatment(s) that optimize growth of nursery-reared A. cervicornis during propagation, 2 statistical models were fitted. First, a linear mixed-effects model allowing for repeated observations on the same fragment to be correlated was fitted using the function lme of the R package 'nlme: linear and nonlinear mixed effects models' (Pinheiro et al. 2014). To allow for temporal correlation among the model residuals, a first-order autoregressive 
correlation structure (corAR1) was applied to the deepest level (on each individual time series) (Zuur et al. 2009). The adequacy of this model was verified by plotting the standardized residuals against (1) the fitted values to check for homogeneity and (2) each explanatory variable to check for violations of independence (Zuur et al. 2007).

Second, a generalized estimation equation allowing for repeated measures and assuming a Poisson error structure was fitted to predict the total number of new branches as a function of fragmentation treatment (i.e. fixed factor). This model was fitted using the function geeglm of the geepack R package (Højsgaard et al. 2006). The model was examined for overdispersion by verifying that the scale parameter $\phi$ was not significantly different from that assumed in a Poisson distribution (i.e. 1) (Crawley 2007). $\phi$ was calculated by squaring the Pearson residuals, adding them up, and dividing the sum by $n-r$, where $n$ was the number of observations and $r$ the number of regression parameters in the model (Zuur et al. 2007). The adequacy of the model was tested by plotting the Pearson residuals against (1) the fitted values to check for homogeneity and (2) each explanatory variable to check for violations of independence (Zuur et al. 2007).

\section{RESULTS}

No partial or whole-colony mortality affected fragmented first-generation colonies or resulting fragments in any of the treatment groups. One of the colonies assigned to the control treatment group detached from the PVC structure and was lost between 0 and $35 \mathrm{~d}$ and was not included in analyses. The growth rate of fragmented first-generation colonies and resulting fragments ranged between 0.01 and $0.06 \mathrm{~cm} \mathrm{branch}^{-1} \mathrm{~d}^{-1}$ (mean $\pm \mathrm{SE}=0.035 \pm$ 0.002). Average annual growth per branch was 12.92 $\pm 0.54 \mathrm{~cm}$. There was no significant effect of the experimental treatments on growth of fragmented first-generation colonies, defined as the proportion of new growth normalized by initial fragment size, over time ( $p=0.934$, Fig. $2 a)$. There was also no significant effect of the experimental treatments on growth of resulting second-generation fragments $(\mathrm{p}=0.864)$. Fragmented first-generation donor colonies acquired

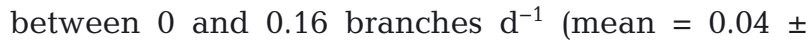
0.01 ), and experimental treatments had no significant effect on the rate of acquisition of new branches for these colonies ( $p=0.976$, Fig. $2 b)$. Data on mean growth and branching per genotype is provided in Table A1 in the Appendix.
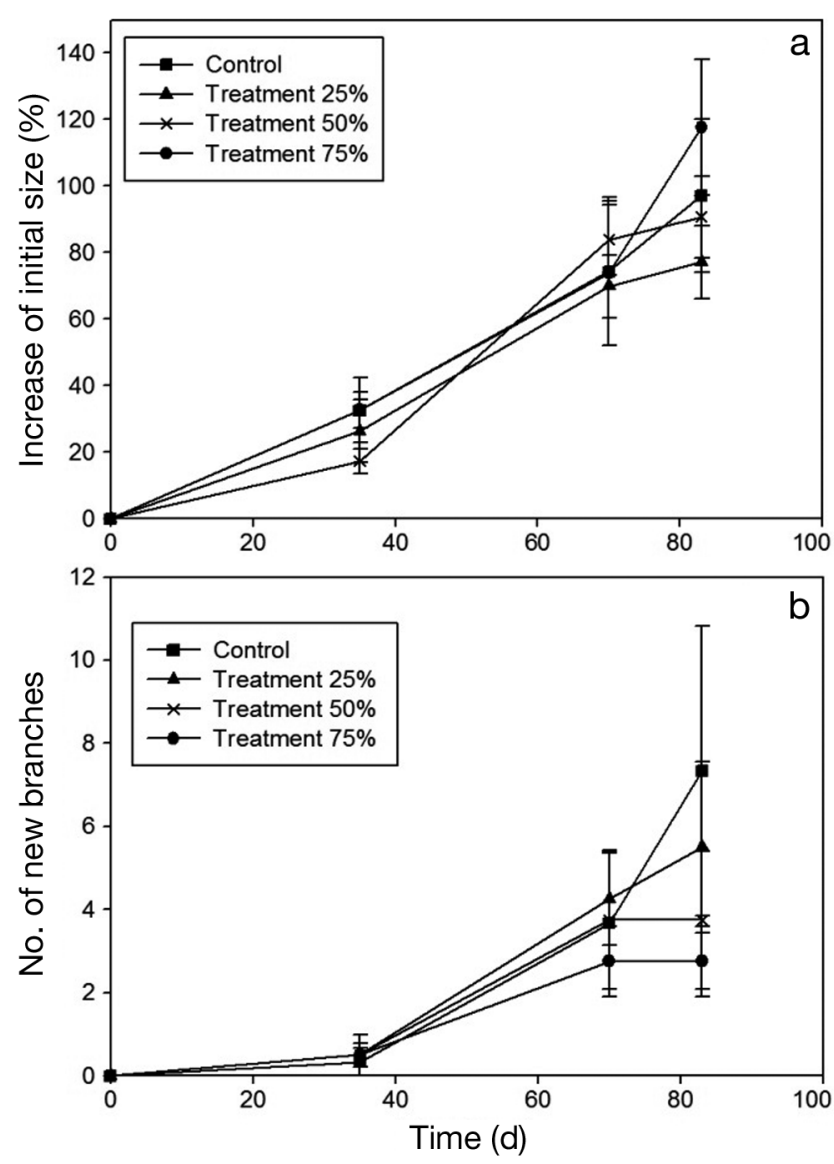

Fig. 2. (a) Proportion of new growth of first-generation donor colonies of staghorn coral Acropora cervicornis standardized by initial size (expressed as a percentage) over time. There was no statistically significant effect of experimental treatment on productivity of first-generation donor colonies over time $(p=0.934)$. (b) Number of new branches acquired over time by treatment. There was no statistically significant effect of experimental treatment on the rate of new branch acquisition $(p=0.976)$. Error bars represent \pm SE

Propagating a first-generation nursery colony of a mean size of $48.19 \pm 4.74 \mathrm{~cm}$ is expected to produce between $2.25 \pm 0.95$ and $6.25 \pm 1.03$ new $5 \mathrm{~cm}$ fragments $\mathrm{yr}^{-1}$ depending on the chosen level of fragmentation (Table 1). When new growth of both fragmented donors and resulting second-generation fragments was combined, the combined amount of new growth increased with the level of fragmentation (Fig. 3).

\section{DISCUSSION}

Rearing coral colonies in a nursery is a relatively simple and increasingly common method for restoring populations of Acropora cervicornis on Carib- 


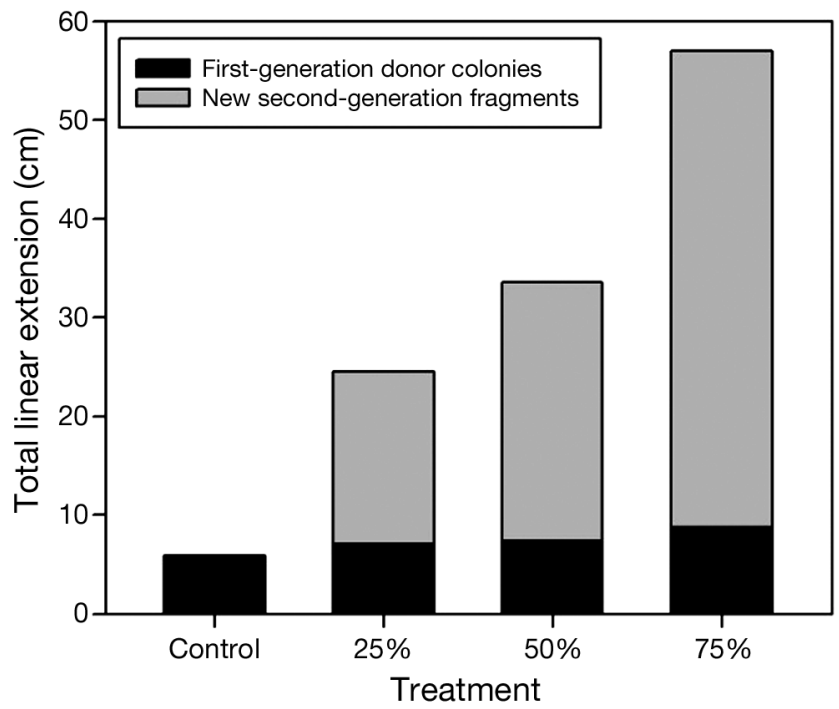

Fig. 3. Total amount of new growth of staghorn coral Acropora cervicornis donor colonies and resulting second-generation fragments after the conclusion of the study ( $83 \mathrm{~d}$ ) by treatment, standardized by initial size

Table 1. Mean productivity $( \pm \mathrm{SE})$ of the staghorn coral Acropora cervicornis nursery per year calculated by combining the growth rates of donors and second-generation fragments, and accounting for the mean number $( \pm \mathrm{SE})$ of $5 \mathrm{~cm}$ second-generation fragments produced by treatment

\begin{tabular}{|lcc|}
\hline $\begin{array}{l}\text { Fragmentation } \\
(\%)\end{array}$ & $\begin{array}{c}\text { Productivity } \\
\left(\mathrm{cm} \mathrm{yr}^{-1}\right)\end{array}$ & $\begin{array}{c}\text { No. of second- } \\
\text { generation fragments }\end{array}$ \\
\hline 0 & $4.17 \pm 1.01$ & 0 \\
25 & $12.65 \pm 3.89$ & $2.25 \pm 0.95$ \\
50 & $17.42 \pm 2.82$ & $3.75 \pm 0.48$ \\
75 & $31.87 \pm 8.04$ & $6.25 \pm 1.03$ \\
\hline
\end{tabular}

bean reefs (Bowden-Kerby 2001, Herlan \& Lirman 2009). The urgent need to minimize reliance on collections from scarce wild colonies demands measures to maximize the intrinsic productivity of nurseries. This study established that up to $75 \%$ of a donor coral can be clipped to create new fragments without negatively affecting the donor's survivorship, growth, or rate of branch acquisition after 83 d. During this study, fragmenting $75 \%$ of the tissue of a first-generation colony resulted in an 8-fold increase in overall nursery productivity when the growth of the fragmented first-generation colony and its resulting second-generation colonies are considered together. No fragmentation threshold beyond which first- and second-generation colonies are likely to suffer mortality or decreased growth was detected in this study, indicating that this value lies beyond $75 \%$. However, these results should be carefully interpreted given the limited temporal scope of the study.

Our results indicated no difference in the rate of addition of new branches among experimental treatments. Due to the relatively short duration of this experiment (i.e. $3 \mathrm{mo}$ ) our study may have failed to capture differences in the rate of branch acquisition, which may emerge over longer temporal scales. A longer study (e.g. $12 \mathrm{mo}$ ) is recommended to determine whether a higher percent of fragmentation results in a faster rate of addition of new branches. If this is the case, the considerations of space availability for propagation approaches using $75 \%$ fragmentation must be regarded as conservative.

A further caveat to consider when interpreting the lack of a treatment effect in our study is the number of samples in the context of statistical power. Given that our experiment was conducted on a small-scale nursery, and aimed to minimize the amount of tissue collected from wild colonies, a small number of samples per treatment was used $(\mathrm{n}=4)$. Such small sample sizes may have precluded the capacity of the statistical tests aimed at detecting treatment effects, particularly when effects were weak and variability was large. Standard deviation (SD) increased with time for both growth (from 0.15 to 0.33 ) and branching rates (from 0.64 to 3.85). A power analysis indicated that with our sample size, differences in growth among treatments had to be $\geq 0.35 \mathrm{~cm} \mathrm{branch}^{-1} \mathrm{~d}^{-1}$ at the beginning of the study and $\geq 0.78 \mathrm{~cm} \mathrm{branch}^{-1} \mathrm{~d}^{-1}$ at the end of our experiment in order to be detected as significant with 0.80 probability. Similarly, for significant differences in branching rate to be detected, these would have had to be $\geq 1.5$ branches $\mathrm{d}^{-1}$ at the beginning of the study and $\geq 9.2$ branches $\mathrm{d}^{-1}$ at the end of the experiment. The magnitude of the observed inter-treatment differences also increased over time, but remained below these thresholds for both growth rate $(\Delta=0.45 \mathrm{~cm}$ branch $\left.^{-1} \mathrm{~d}^{-1}\right)$ and branching rate $(\Delta=0.17-4.6$ branches $\mathrm{d}^{-1}$ ). This indicates that our study would have benefited from larger sample sizes $(n=12)$ to maximize the chances of detecting treatment effects. Larger sample sizes will be possible in larger nurseries, or at a future stage when the Little Cayman nursery is larger and more developed.

Mortality was not observed among fragmented first-generation colonies or resulting fragments during the course of this study. This is consistent with other A. cervicornis nurseries in the Caribbean region, which typically exhibit high survivorship 
(i.e. $>70 \%$ ) during the first year after propagation (Young et al. 2012). Growth of branches monitored in this study was consistent with published measurements for A. cervicornis (Tunnicliffe 1983). High water quality in Little Cayman and a lack of environmental disturbance during the course of the study likely contributed to the lack of mortality and positive growth trend observed among the nursery population.

Ward (1995) found that fragmentation has the potential to increase susceptibility of fragmented donors and resulting fragments to stressors such as storms and disease outbreaks. For this reason, we recommend avoiding fragmentation during peak hurricane season (i.e. June to November), when storms have a higher probability of directly damaging corals and leading to spikes in disease prevalence (Knowlton et al. 1981, Brandt et al. 2013, Miller et al. 2014).

Despite the lack of observed mortality or decreased growth and branching, fragmentation has been found to have long-term impacts on fecundity in some coral species (Smith \& Hughes 1999, Lirman 2000, Okubo et al. 2007). Temporary loss of fecundity is thought to be a result of corals shifting resources from reproduction to repair and growth following fragmentation (Szmant 1986, Lirman 2000, Okubo et al. 2007). In A. palmata, naturally fragmented colonies and resulting fragments did not produce gametes until 4 yr after fragmentation (Lirman 2000). Further studies are required to determine the effect of fragmentation on fecundity in A. cervicornis. Until more information on fecundity following fragmentation is available for A. cervicornis, it may be prudent to avoid fragmenting nursery colonies immediately prior to outplanting to minimize any potential recovery time.

Determining the optimal level of fragmentation during propagation must involve careful analysis of the availability of space in the nursery, the cost involved in ensuring all structures remain clean and functional, and local restoration goals. Fragmenting large portions of first-generation colonies would obviously produce the largest number of new corals but would require the largest amount of space and may exceed the number of transplants required locally. The results presented here may serve as guidelines to extrapolate short-term productivity of small-scale nurseries over different time scales, thus enabling restoration managers to adjust nursery productivity to meet specific conservation goals. Nursery expansion or frequency of transplantation events can therefore be planned to suit both nursery space avail- ability and feasible numbers of transplants required in local reefs.

Genetic diversity should also be carefully considered during fragmentation. This study did not allow us to test the effect of genotype on productivity due to low replication within treatments. However, differences in genotype have been shown to impact growth rate and survivorship (Bowden-Kerby 2008, Griffin et al. 2012, Lirman et al. 2014). Therefore, individual growth rates of genotypes should be monitored in order to detect genotypic differences, and fast-growing genotypes should be fragmented less frequently or fragmented to produce fewer new colonies. This type of strategy will prevent genetic imbalances within nurseries. It is important to maintain genetically diverse populations within nurseries to avoid adverse conditions during transplantation such as founder effects or genetic swamping (Baums 2008).

A maximum fragmentation approach may be ideal for expanding a small-scale nursery provided there is adequate space availability. It is important to note that the results presented here are only applicable to propagation within a coral nursery, and a $75 \%$ fragmentation strategy is likely not optimal for removal of tissue from a wild donor colony given risks to fecundity and increased susceptibility to storm damage and disease. Our study can be used to plan nursery development and expansion, thus facilitating restoration and conservation efforts for A. cervicornis throughout the Caribbean region. In addition to species-specific considerations, these findings could be relevant for other branching coral species with similar growth rates and asexual reproduction strategies, but may not be appropriate for species less adapted to natural fragmentation.

Acknowledgements. We thank John Bothwell of the Cayman Islands Department of Environment (CIDOE), who was instrumental in providing the legal and logistical framework needed to construct the nursery and conduct this study. We also thank Samantha Hamilton for assistance with graphics, and Heather Murray and Becks Green for assistance in the field. Collections from adult colonies were conducted in conjunction with and under the supervision of CIDOE. Funding for this study was provided by the Darwin Initiative (DPLUS010) and the Dart Foundation (Cayman Islands).

\section{LITERATURE CITED}

Alvarez-Filip L, Dulvy NK, Gill JA, Côté IM, Watkinson AR (2009) Flattening of Caribbean coral reefs: region-wide declines in architectural complexity. Proc R Soc Lond B Biol Sci 276:3019-3025 
Aronson RB, Precht WF (2001) White-band disease and the changing face of Caribbean coral reefs. Hydrobiologia 460:25-38

Baums IB (2008) A restoration genetics guide for coral reef conservation. Mol Ecol 17:2796-2811

Bellwood DR, Hughes TP, Folke C, Nyström M (2004) Confronting the coral reef crisis. Nature 429:827-833

Bowden-Kerby A (2001) Low-tech coral reef restoration methods modeled after natural fragmentation processes. Bull Mar Sci 69:915-931

Bowden-Kerby A (2008) Restoration of threatened Acropora cervicornis corals: intraspecific variation as a factor in mortality, growth, and self-attachment. Proc 11th Int Coral Reef Symp, Ft. Lauderdale, FL, p 1194-1198

Brandt ME, Smith TB, Correa AMS, Vega-Thurber R (2013) Disturbance driven colony fragmentation as a driver of a coral disease outbreak. PLoS ONE 8:e57164

Bythell J, Sheppard C (1993) Mass mortality of Caribbean shallow corals. Mar Pollut Bull 26:296-297

Crawley M (2007) The R Book. John Wiley \& Sons, Chichester

> Done TJ (1992) Phase shifts in coral reef communities and their ecological significance. Hydrobiologia 247:121-132

Epstein N, Bak RPM, Rinkevich B (2003) Applying forest restoration principles to coral reef rehabilitation. Aquat Conserv 13:387-395

Gardner TA, Côté IM, Gill JA, Grant A, Watkinson AR (2003) Long-term region-wide declines in Caribbean corals. Science 301:958-960

Griffin S, Spathias H, Moore TD, Baums I, Griffin BA (2012) Scaling up Acropora nurseries in the Caribbean and improving techniques. Proc $12^{\text {th }}$ Int Coral Reef Symp, Cairns, p 1-5

Herlan J, Lirman D (2009) Development of a coral nursery program for the threatened coral Acropora cervicornis in Florida. Proc $11^{\text {th }}$ Int Coral Reef Symp, Ft. Lauderdale, FL, p 1244-1247

Højsgaard S, Halekoh U, Yan J (2006) The R Package geepack for Generalized Estimating Equations. J Stat Softw 15:1-11

> Hughes TP (1994) Catastrophes, phase shifts, and largescale degradation of a Caribbean coral reef. Science 265: $1547-1551$

Jackson JB, Kirby MX, Berger WH, Bjorndal KA and others (2001) Historical overfishing and the recent collapse of coastal ecosystems. Science 293:629-637

Johnson ME, Lustic C, Bartels E, Baums IB and others (2011) Caribbean Acropora restoration guide: best practices for propagation and population enhancement. The Nature Conservancy, Arlington, VA

> Johnson MK, Holbrook SJ, Schmitt RJ, Brooks AJ (2011) Fish communities on staghorn coral: effects of habitat characteristics and resident farmerfishes. Environ Biol Fishes 91:429-448

Knowlton N, Lang JC, Rooney MC, Clifford P (1981) Evidence for delayed mortality in hurricane-damaged Jamaican staghorn corals. Nature 294:251-252

Kojis BL, Quinn NJ (2001) The importance of regional differences in hard coral recruitment rates for determining the need for coral restoration. Bull Mar Sci 69:967-974

Lidz BH, Zawada DG (2013) Possible return of Acropora cervicornis at Pulaski Shoal, Dry Tortugas National Park, Florida. J Coast Res 29:256-271

Lirman D (2000) Fragmentation in the branching coral Acropora palmata (Lamarck): growth, survivorship, and reproduction of colonies and fragments. J Exp Mar Biol Ecol 251:41-57

Lirman D, Thyberg T, Herlan J, Hill C and others (2010) Propagation of the threatened staghorn coral Acropora cervicornis: methods to minimize the impacts of fragment collection and maximize production. Coral Reefs 29:729-735

Lirman D, Schopmeyer S, Galvan V, Drury C, Baker AC, Baums IB (2014) Growth dynamics of the threatened Caribbean staghorn coral Acropora cervicornis: influence of host genotype, symbiont identity, colony size, and environmental setting. PLoS ONE 9:e107253

Miller MW, Lohr KE, Cameron CM, Williams DE, Peters EC (2014) Disease dynamics and potential mitigation among restored and wild staghorn coral, Acropora cervicornis. PeerJ 2:e541

> Mumby PJ, Hastings A, Edwards HJ (2007) Thresholds and the resilience of Caribbean coral reefs. Nature 450: 98-101

Nagelkerken I, Nagelkerken WP (2004) Loss of coral cover and biodiversity on shallow Acropora and Millepora reefs after 31 years on Curaçao, Netherlands Antilles. Bull Mar Sci 74:213-223

Nedimyer K, Gaines K, Roach S (2011) Coral tree nursery: an innovative approach to growing corals in an oceanbased field nursery. AACL Bioflux 4:442-446

NMFS (National Marine Fisheries Service) (2006) Endangered and threatened species: final listing determinations for elkhorn coral and staghorn coral. Fed Regist 71: 26852-26861

Okubo N, Motokawa T, Omori M (2007) When fragmented coral spawn? Effect of size and timing on survivorship and fecundity of fragmentation in Acropora formosa. Mar Biol 151:353-363

Paddack MJ, Reynolds JD, Aguilar C, Appeldoorn RS and others (2009) Recent region-wide declines in Caribbean reef fish abundance. Curr Biol 19:590-595

Pinheiro J, Bates D, DebRoy S, Sarkar D, R Core Team (2014) nlme: linear and nonlinear mixed effects models. R package version 3.1-118. Available at http://CRAN.Rproject.org $/$ package $=$ nlme

Rinkevich B (1995) Restoration strategies for coral reefs damaged by recreational activities: the use of sexual and asexual recruits. Restor Ecol 3:241-251

Rinkevich B (2000) Steps toward the evaluation of coral reef restoration by using small branch fragments. Mar Biol 136:807-812

Rogers CS, Beets J (2001) Degradation of marine ecosystems and decline of fishery resources in marine protected areas in the US Virgin Islands. Environ Conserv 28: 312-322

Sheppard C, Dixon DJ, Gourlay M, Sheppard A, Payet R (2005) Coral mortality increases wave energy reaching shores protected by reef flats: examples from the Seychelles. Estuar Coast Shelf Sci 64:223-234

Smith LD, Hughes TP (1999) An experimental assessment of survival, re-attachment and fecundity of coral fragments. J Exp Mar Biol Ecol 235:147-164

Szmant AM (1986) Reproductive ecology of Caribbean reef corals. Coral Reefs 5:43-54

Tunnicliffe V (1983) Caribbean staghorn coral populations: pre-Hurricane Allen conditions in Discovery Bay, Jamaica. Bull Mar Sci 33:132-151

Ward S (1995) The effect of damage on the growth, reproduction and storage of lipids in the scleractinian coral 
Pocillopora damicornis (Linnaeus). J Exp Mar Biol Ecol 187:193-206

Woodley JD, Chornesky EA, Clifford PA, Jackson JBC and others (1981) Hurricane Allen's impact on Jamaican coral reefs. Science 214:749-755

Young CN, Schopmeyer SA, Lirman D (2012) A review of reef restoration and coral propagation using the threat- ened genus Acropora in the Caribbean and western Atlantic. Bull Mar Sci 88:1075-1098

Zuur A, Ieno E, Smith GM (2007) Analysing ecological data. Springer, New York, NY

Zuur A, Ieno EN, Walker NJ, Saveliev AA, Smith GM (2009) Mixed effects models and extensions in ecology with R. Springer, New York, NY

Appendix. Table A1. Mean \pm SE growth rate (measured as $\mathrm{cm}$ new growth standardized by initial size) and branching rate (mean number of new branches) per genotype (A-D) of staghorn coral Acropora cervicornis at different survey times

\begin{tabular}{|lccc|}
\hline Genotype & $35 \mathrm{~d}$ & $70 \mathrm{~d}$ & $83 \mathrm{~d}$ \\
\hline Growth rate & & & \\
A & $0.19 \pm 0.05$ & $0.59 \pm 0.09$ & $0.72 \pm 0.09$ \\
B & $0.31 \pm 0.13$ & $0.89 \pm 0.17$ & $1.19 \pm 0.03$ \\
C & $0.21 \pm 0.06$ & $0.56 \pm 0.14$ & $1.16 \pm 0.04$ \\
D & $0.27 \pm 0.01$ & $0.95 \pm 0.20$ & $1.06 \pm 0.30$ \\
Branching rate & & & \\
B & $0.00 \pm 0.00$ & $1.33 \pm 0.33$ & $3.75 \pm 2.43$ \\
C & $0.75 \pm 0.48$ & $3.00 \pm 1.08$ & $5.33 \pm 1.76$ \\
D & $0.33 \pm 0.33$ & $5.67 \pm 1.33$ & $7.67 \pm 2.91$ \\
\hline
\end{tabular}

Editorial responsibility: Dave Roberts, Canterbury, UK
Submitted: August 4, 2014; Accepted: December 30, 2014 Proofs received from author(s): March 24, 2015 